\title{
Seismic Policy, Operations, and Research Uses for a Building Inventory in an Earthquake-Prone City
}

\author{
Ken Elwood $^{1} \cdot$ Olga Filippova $^{2} \cdot$ Ilan Noy $^{3} \cdot$ Jacob Pastor Paz $^{3}$
}

Accepted: 10 October 2020/Published online: 22 October 2020

(C) The Author(s) 2020

\begin{abstract}
After the 2016 New Zealand Kaikoura Earthquake, the absence of information about the state of buildings in Wellington proved to be a source of significant policy uncertainty. Authorities did not know what damages to expect and therefore how to react, and policies needed to be formulated without a clear quantification of the risks. Moreover, without detailed knowledge of the existing buildings, it was difficult to assess what the available legal and regulatory tools can achieve and choose among them. We describe the creation of a building inventory database for Wellington initiated by the authors. This database aims to assist the generation of research on the risks, impacts, and viable solutions for reducing future seismic risk in Wellington's central business district (CBD). The database includes structural, economic, and market information on virtually every significant building in the CBD. Its primary purposes are: to collate and provide the best available information about the expected seismic performance of the existing building stock; to assess the impact of possible multiple building failures due to a seismic event; to describe a viable cost-effective path for seismic retrofitting; and to inform the design of a regulatory structure that can facilitate this resilience-building agenda.
\end{abstract}

Ilan Noy

ilan.noy@vuw.ac.nz

1 School of Engineering, The University of Auckland, Auckland 1142, New Zealand

2 Business School, The University of Auckland, Auckland 1142, New Zealand

3 School of Economics, Victoria University of Wellington, Wellington 6140, New Zealand
Keywords Building inventory $\cdot$ Building standards · Disaster risk assessment - Earthquake-prone city $\cdot$ Retrofit

\section{Introduction}

New Zealand shares its seismic risk profile with many other countries that are located along the Pacific Ring of Fire. Approximately $81 \%$ of the world's largest earthquakes have occurred along the ring, resulting in it being labelled as the most earthquake-prone region in the world (USGS 2014). Awareness of the risks posed by such seismic activity has heightened in the recent past as a result of the several significant earthquakes that have occurred along these fault lines. These include the 2010 earthquake in Chile and the March 2011 earthquake in Japan and ensuing tsunamis after both events. New Zealand itself is on high alert following a string of destructive events in the Canterbury region in 2010-2011, the 2013 Seddon Earthquake, and the 2016 Kaikoura Earthquake.

Wellington, New Zealand's capital city, is situated just north of where two tectonic plates, the Pacific and Australian plates, collide (see Fig. 1). The Wellington fault runs through the central part of the city, passing under lifeline infrastructure and densely developed areas (Fig. 1). Inherently, the city is at high risk of major earthquakes and is more exposed than any other part of the country, having experienced numerous earthquakes in the past. Therefore, developing and maintaining an up-to-date comprehensive inventory that contains details of the area's building stock is important for seismic risk assessment and management. Surprisingly, this has not been previously possible.

The 2016 Kaikoura Earthquake was the most recent significant earthquake to impact Wellington. The 


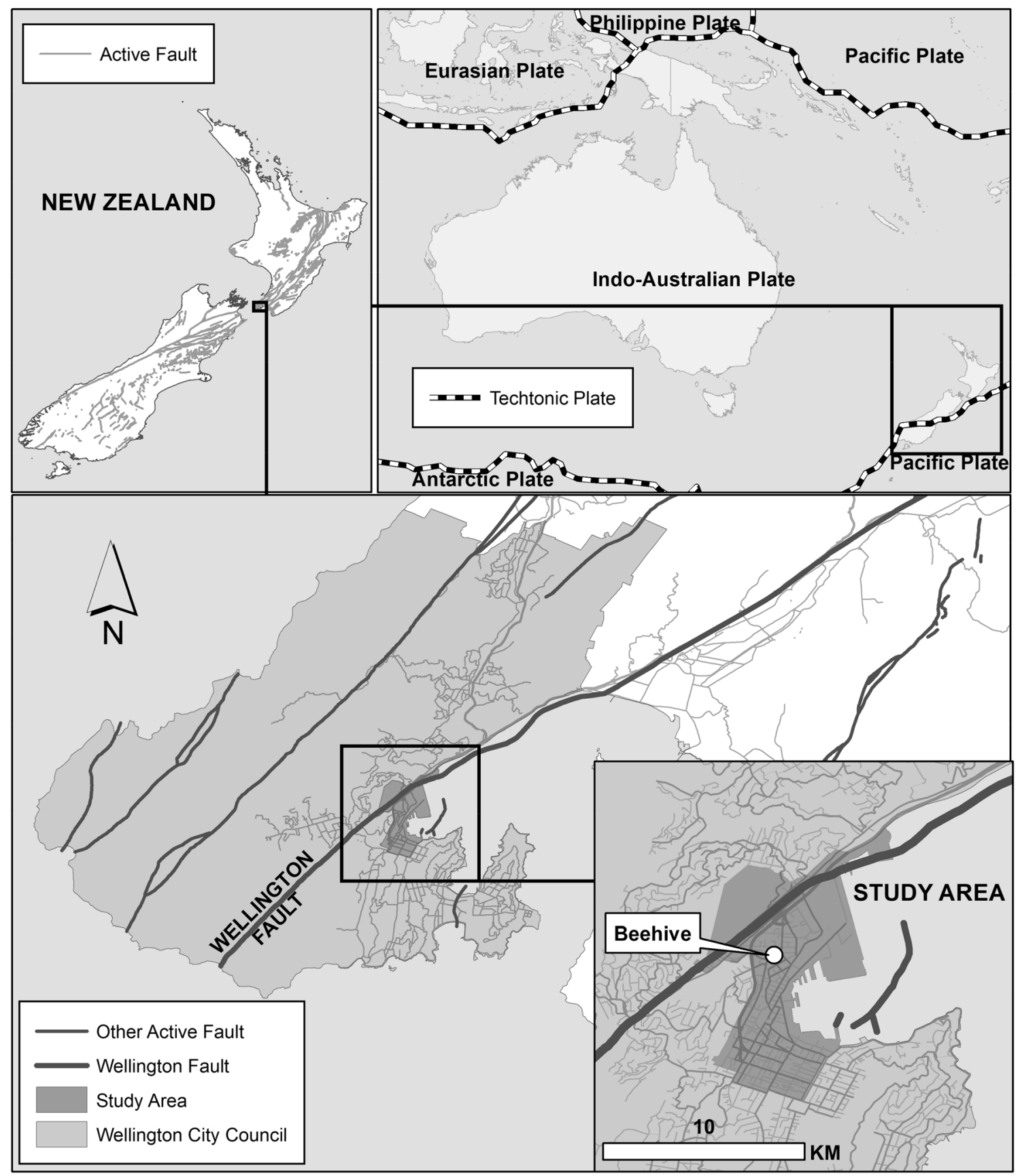

Fig. 1 Location of New Zealand active faults and extent of the study area within Wellington Source: New Zealand active faults sourced from Langridge et al. (2016)

earthquake had a magnitude of $7.8\left(\mathrm{M}_{\mathrm{w}}\right)$ and occurred on 14 November 2016. Although its epicenter was in the South Island, about $200 \mathrm{~km}$ southwest of Wellington, it damaged numerous buildings across the city. In the immediate aftermath of the earthquake about $11 \%$ $\left(167,000 \mathrm{~m}^{2}\right)$ of the city's office space was closed for assessment, thereby forcing relocations of thousands of workers from their offices (Harris 2016). To-date, 20 mostly office buildings had been demolished or remain vacant. Additionally, 10 were initially closed but then reopened upon further inspections (Fig. 2). Several years on, structural vulnerabilities are still being discovered, forcing building closures. Most recently, in March 2019, the Central Library was closed "indefinitely" due to earthquake-risk concerns.

Most of the damaged buildings were located in the central business district (CBD) of the city. A large concentration was located around the port, on reclaimed land 


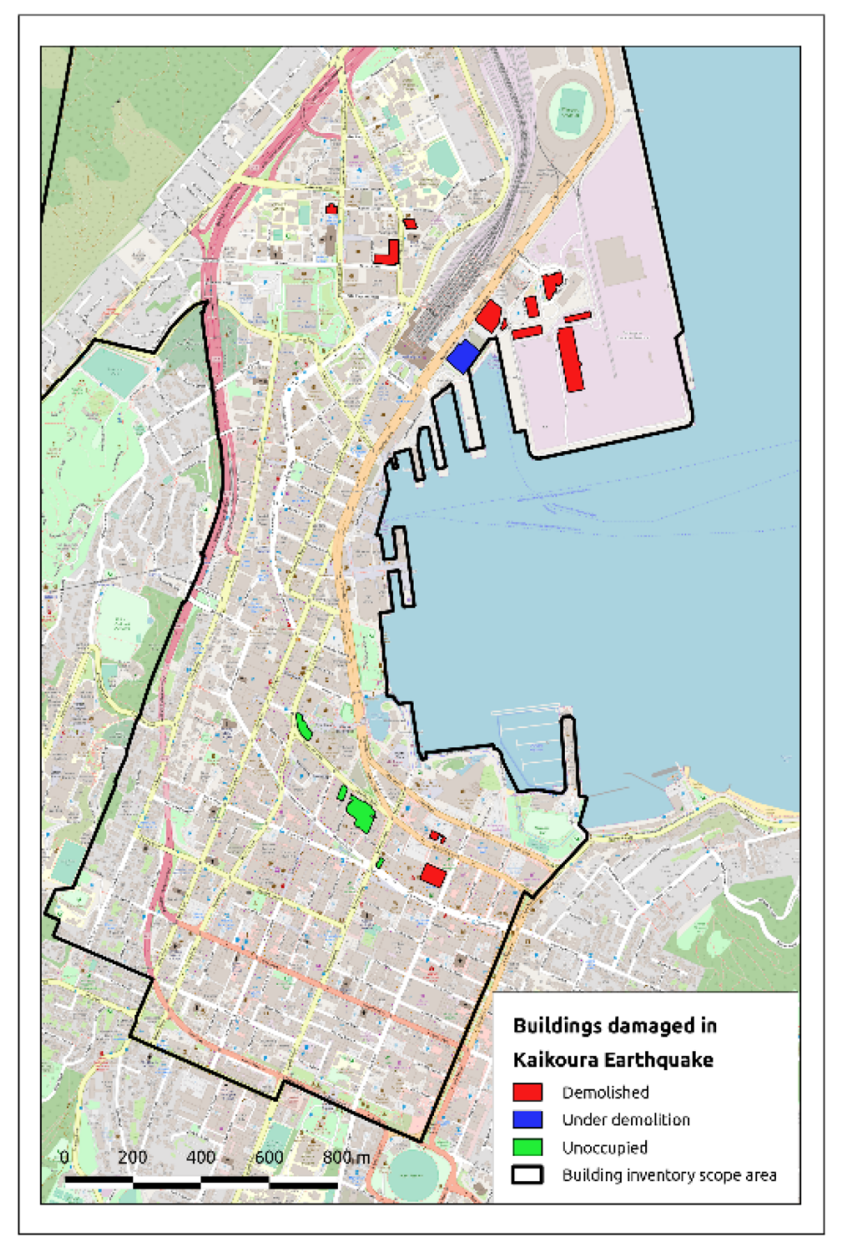

Fig. 2 Locations of damaged buildings in Wellington (as of February 2019) Source: Wellington City Council

or land along a shoreline that was uplifted by a strong nineteenth century earthquake. Other damage hotspots were in the Thorndon and Te Aro basins. Most affected buildings were moment-resisting concrete frame buildings between six and 15 floor levels constructed after 1980 (Brundson et al. 2017), while prior to the earthquake the highest risk was assessed to be in older unreinforced masonry buildings. As such, most previous data collection and policy efforts had focussed on this older building stock (Russell and Ingham 2010; Falcon Consulting 2019). This led to the realization that the city has unrecognized vulnerabilities and that comprehensive information about the building stock is not available, so that it was impossible to rapidly quantify these newly-identified vulnerabilities in the immediate aftermath of the earthquake.

As an example, the Statistics House building in Wellington CBD suffered structural failure with partial collapse of two floors. The building, which was only 12 years old at the time of the earthquake, was eventually demolished. Fortunately, there were no injuries, as was the case with all other buildings that had structural or non- structural failures. The earthquake occurred just after midnight and most of the damage occurred in non-residential buildings. Following the failure in Statistics House, the Wellington City Council (WCC) identified buildings with characteristics similar to it, specifically focusing on precast floor systems, and ordered owners of those buildings to conduct further investigations. Eventually, 64 buildings were identified for intensive investigation within the Targeted Damage Evaluation (TDE) program focusing on multi-story buildings of reinforced concrete, with precast concrete slab floors with various levels of structural damage. The buildings subject to the TDE program spread throughout the inner city.

Thus, the 2016 Kaikoura Earthquake highlighted structural vulnerabilities of mid-size reinforced concrete buildings that were not sufficiently appreciated before the event. Before November 2016, most of the seismic risk was perceived to be concentrated in older un-reinforced masonry buildings or reinforced concrete buildings built prior to 1976. These buildings were acknowledged to have inherent seismic vulnerability and were often assessed as "earthquake prone." Earthquake prone is a legal term in New Zealand that places obligations for retrofitting of these building within time frames specified in The Building (Earthquake-Prone Buildings) Amendment Act of 2016. ${ }^{1}$ Statistics House, Customs House, Defense House, and the Bank of New Zealand Buildings were all buildings that were built since the 1990s, were perceived to be low risk, were all not considered earthquake-prone, but all failed in this event.

Several other large modern commercial buildings constructed since 1990 also suffered irreparable damage in the 2016 Kaikoura Earthquake. Such buildings were perceived to be low risk, further highlighting the need to understand the vulnerabilities in the existing building stock in the city, and consider which buildings pose substantial risk that should be mitigated. In this context, it is important to note that it was the collapse of one concrete building in the February 2011 Christchurch Earthquake (the CTV building constructed in 1986) that accounted for about $60 \%$ of the 185 fatalities. This collapse was the highest mortality natural hazard event in New Zealand's modern history.

Beyond the life-safety risk associated with mid-size concrete frame office buildings, both the Christchurch and Kaikoura Earthquakes damaged numerous concrete buildings, resulting in wide-ranging costs imposed on property owners (for example, through loss of rental income or uninsured damage), building occupiers (for example, through business interruption), and insurers. These earthquake events and their aftermaths thus exposed the paucity

\footnotetext{
$\overline{1}$ http://www.legislation.govt.nz/act/public/2016/0022/latest/ DLM5616102.html.
} 
of information that local emergency managers, city planners, and other stakeholders have about the existing stock of buildings. It is the paucity of this kind of information that the database described here aims to ameliorate.

Our initial intention, as representatives of the QuakeCoRE project, in putting together the building inventory database was to inform a multi-disciplinary Wellingtoncentered project. The database contains information on the location, age, size, structural systems, known vulnerabilities/deficiencies, use, and occupancy of multi-story buildings in the CBD and will be used to facilitate multidisciplinary research whose aims are: (1) to provide best scientific knowledge about the expected seismic performance of concrete buildings; (2) to inform the design of a regulatory structure that can facilitate the reduction of risk associated specifically with earthquake-vulnerable concrete buildings; (3) to assess the impact of multiple building failures including the downstream consequences of associated cordoning; and (4) to provide a path for prioritization of seismic retrofitting that will lead to increased levels of seismic resilience in the city.

For that purpose, contact with owners of the various datasets included in the database was initiated, and the project started collecting and collating the data that were available in early 2018, combining information from 11 sources. To verify information about building height and occupancy, a sidewalk survey was commissioned. In what follows, we first describe previous attempts to collect building inventory databases elsewhere (as these efforts are described in the literature), we then describe the structure of the database (Sect. 3), what it contains (Sect. 4), what are its intended uses (Sect. 5), and finalize our discussion with some concluding remarks in Sect. 6.

\section{The Literature}

Other examples of such databases of buildings and prioritization of retrofits programs include: Comerio (2000) for building assets owned by the University of California, Berkeley; Walsh et al. $(2016,2017)$ on an asset database of buildings owned by Auckland City Council (the largest city in New Zealand); Anagnos et al. (2016) on an inventory of nonductile concrete buildings in the city of Los Angeles and Anagnos et al. (2012) for other cities in California; Yathon et al. (2017) for a detailed inventory of pre-1980 high-rise reinforced concrete buildings in Vancouver (Canada); Palermo et al. (2018) for a survey on similar European efforts; Hancilar et al. (2018) for a building inventory assessment in Muscat (Oman); Jaiswal and Wald (2008) who describe inventory work undertaken in the United States for the construction of the HAZUS model; Yepes-Estrada et al. (2017) who describe the construction of a similarly motivated database in Latin America, and Sucuoğlu et al. (2015) and Grant et al. (2007) who describe prioritization schemes in Turkey and Italy, respectively.

Each one of these works takes a somewhat different approach, but ultimately they all conduct pre-earthquake seismic resilience needs assessments for various sets of assets. Many of the earlier efforts, as described in Jaiswal and Wald (2008), were aimed at developing the required inputs into seismic risk modeling. In particular, these efforts involved the collection of information on representative buildings and their uses, and the use of statistical extrapolation techniques to construct from these more comprehensive databases of representative buildings and their expected occupancies (for example, Kircher et al. 2006). In circumstances where very little building-specific data were available, for example for Muscat (Oman), all the collected data were based on extrapolations from the identified statistical distributions and remote sensing data such as satellite imageries (Haniclar et al. 2018).

In many cases, the inventories were therefore not based on accurate information on specific buildings, but rather on statistical distributions of building types in different locations. Even when the primary units of observation were specific buildings, the inventory databases frequently constituted a large set, so that information on specific buildings was deduced from statistical information, either collected for the specific needs of the project, or available from other sources (for example, Walsh et al. 2016, 2017).

In other cases, the data collection efforts targeted a specific subset of the existing buildings, specifically focusing on the ones that were perceived to constitute the highest risk, or included a specific type of vulnerability that the database creators chose to focus on. This is the case, for example, for Comerio and Anagnos (2012) who collected some data on all nonductile concrete buildings in the city of Los Angeles and then used meta-data to deduce about their vulnerabilities and their spatial distributions. In contrast, Yathon et al. (2017) develop a building-specific inventory of pre-1980 nonductile concrete shear wall buildings seven or more stories high, using information sourced primarily from structural drawings.

Anagnos et al. (2012) summarize several inventory collection efforts in the U.S. state of California (targeting mostly older concrete buildings), and describe how each effort was contingent on the financial, human, and technical resources that were available to construct the inventory. As in our case, in some of these instances the efforts were even complemented with individual street-level survey of the individual buildings contained in the inventory database. Anagnos et al. (2012) also suggests the new sources of data, and data collection methods (for example, remote sensing) are rapidly improving our abilities to collect building inventory datasets that can assist in seismic 
resilience decision making. Theilen-Willige et al. (2012) also analyzes the capacity of remote sensing data to identify asset inventories, in their case focusing on infrastructure.

Equally promising, we believe, is our current ability to store large amounts of data in accessible formats that will allow researchers, practising engineers, policymakers, and other stakeholders to access all the data that might be available on a specific building, precinct, neighborhood, or any other level of aggregation. In particular, we can now store pictures, copies of plans and drawings, numerical and street-survey information, and other data in linked and easily managed formats that can be accessed from anywhere. Accessibility is important in our project, as it was done in collaboration with the Wellington City Council, and is intended for use also by the emergency management authorities, should they require information in the aftermath of a future event.

It is also instructive to note that almost all of these building and infrastructure inventory projects described above were ultimately aimed at developing risk models based on the hazard, exposure, and vulnerability framework. Our database aims to go a step further and include data that are not only useful for assessing direct exposure and vulnerability (mostly structural and seismic engineering data) but also data that are instructive about the social, political, and economic role of each asset, so that its importance, and the implications of its current risk profile can be interrogated, and potentially acted on to change that profile.

\section{The Database}

As is seen in Fig. 3, the database is embedded within a Geographic Information System (GIS) viewer that allows approved users access to all the information online or for download. Different levels of access are granted as some of the data are commercially sensitive or are not part of the public record.

The inventory contains critical geo-referenced structural and occupancy-related information that is building-specific and present a useful description of the existing building stock in the Wellington CBD. Building information is vetted through existing structural drawings and visual inspections through street surveys. Additionally, all data can be readily updated, and all updates are time-stamped.

The database is to be continually stored and curated from a server outside of Wellington, and will be accessible from anywhere, so that it will remain available during the emergency phase of a seismic event, should one occur. In what follows, we present some of the meta-data about the building stock that are within the scope area and identify future directions for this database and its uses.

\section{The Information in the Database}

The inventory information included in this database contains spatial and attribute data. The attribute data cover structural (for example, lateral and floor systems), nonstructural (for example, building size, age, façade, exterior cladding), and occupancy (for example, occupant industry classification, primary building use) related information for each building. Building footprints (polygons representing building rooftop outlines, generated by Wellington City Council) are used as the base layer to which attribute characteristics are merged. The structural engineering characteristics of the buildings are obtained from several sources-more discussion of these is available in a companion paper that describes the history of construction technologies used in the city (Puranam et al. 2019). One advantage of the database, for the purposes described in this article, is the addition of other information on these buildings, specifically occupant details.

Several private firms conduct regular surveys of commercial space availability within the Wellington CBD. The primary purpose of these surveys is to update the supply of commercial office space and identify space available for rent. Colliers International supplied their June 2016 (preKaikoura) and June 2017 (post-Kaikoura) vacancy surveys for the current version of the database. The Colliers dataset contains 974 buildings covering various building uses; commercial (office, retail, accommodation), residential, and other (for example, utilities, transport, religious, and so on). Detailed information on occupants (tenants) is only collected for office buildings and contains information such as building address and name, tenant/occupant company name by floor level, amount of space occupied by floor level, vacant spaces, and an indicator of the building's quality in relation to the market (assigned using the standard Property Council of New Zealand office quality grading-A, B, C). The area covered by the survey is divided into five precincts: City Core, Fringe, Thorndon, Harbour Quays, and Te Aro (Fig. 4).

One early problem we encountered is that most datasets do not comprehensively cover the whole building stock in the target area. For example, as can be seen in Fig. 4, the Colliers dataset only includes information about $25 \%$ of the building stock identified in the Wellington City Council building footprint dataset. Colliers survey aims to cover office buildings, so it will not include information, for example, on storage facilities, or buildings that have other uses (for example, religious houses of worship or educational institutions). 


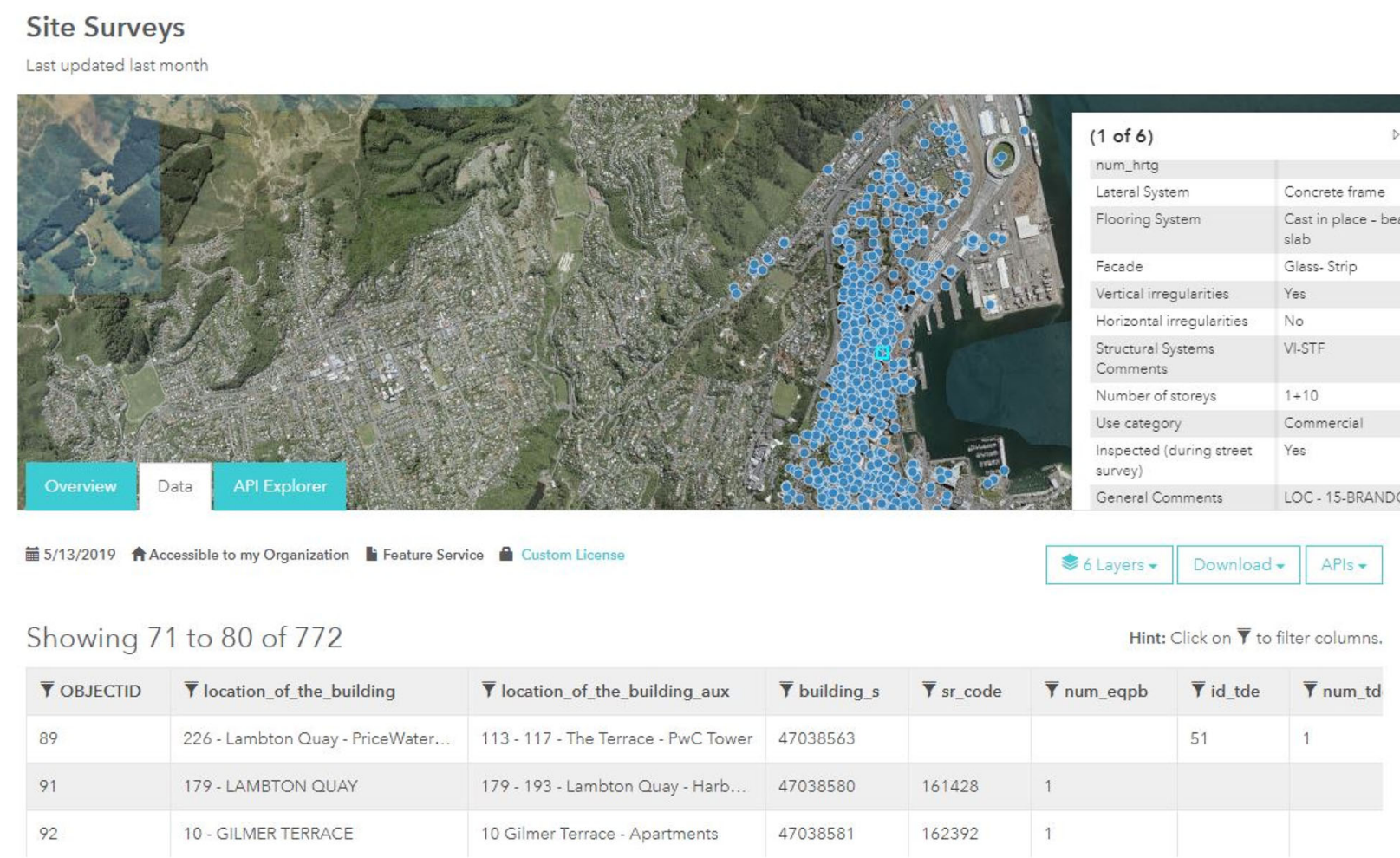

Fig. 3 Database with map viewer

Occupancy type (in broad industry categories) of tenants/businesses operating in office buildings is not included in the Colliers dataset, but was needed to be assigned to each tenant for use in assessments of each building's role in the economy of the city. For that purpose, we combined the Colliers dataset with the New Zealand Standard Industrial Output Categories (NZSIOC) classification system to create an occupancy-by-sector data. This was done by assigning each tenant an industry classification code as designated by NZSIOC. We based these classifications on online search using company names and addresses in order to identify the services they provide. We assigned a level 4 NZSIOC classification to the occupants to retain the high level of resolution this dataset provides. For example, "Travel Harbour City" is a travel agency in Wellington. Thus, it was assigned the MN211 from the NZSIOC codes.

We also record all these buildings that appear on the New Zealand Heritage List/Rārangi Kōrero as having a Heritage designation. This designation places some legal restrictions on what modifications owners can do in the building, and is thus pertinent to some of the potential users of this database. In future updates of the database, we hope to include additional information, including information about telecommunication and energy use within each building from the utility companies, and potentially other data that might be useful for any of the intended uses of the database. Ultimately, the inventory dataset aims to provide researchers with building-specific information that has high level of accuracy, so this is an additional criteria in our choice. We specifically elected not to use extrapolation techniques, as is often done in inventory databases, as the intention of the project is for each building-specific data to also be useful for users who want to focus on a specific building (or a group of buildings).

As mentioned above, the inventory is built from multiple datasets that have varying degree of coverage and reliability. To assist with consolidation and verification, street surveys were conducted to validate and fill gaps in the information obtained from these datasets. Data collectors were supplied with tablets pre-loaded with the building inventory GIS viewer and were trained to verify the information therein. In particular, they were asked to look for any evidence of current retrofits or other exterior building works, types of exterior cladding, number of stories, and ground and upper floor uses. In addition, collectors took photos of the exterior and interior (ground floor/lobby) and these are also available through the database GIS viewer. 
Fig. 4 Colliers precinct boundaries and representation of buildings within the study area Source: Colliers Vacancy Survey and authors. Base map: OpenStreetMap

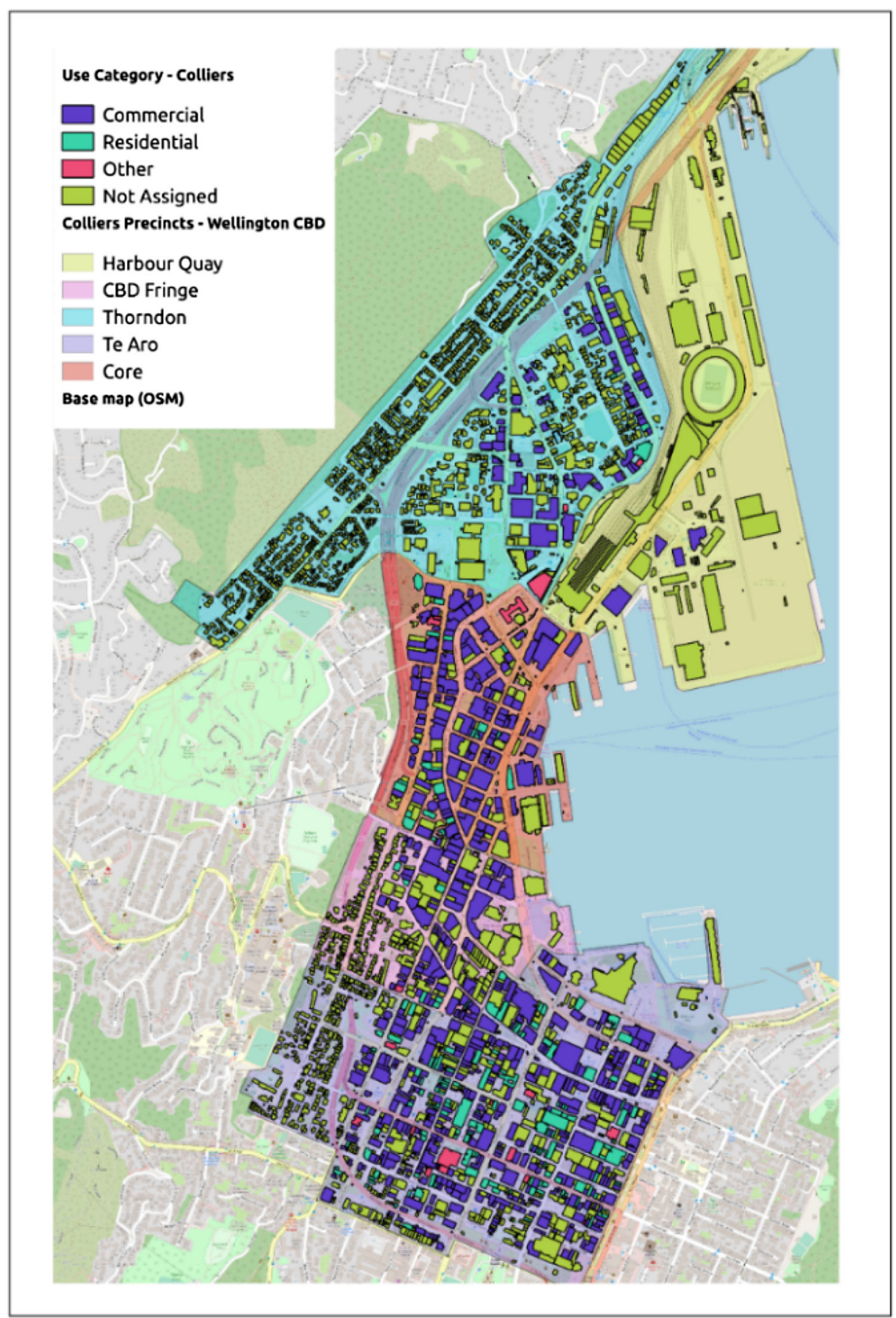

\section{The Uses of the Database}

As originally conceived, the database was initially targeted to inform the answers to four specific questions:

(1) Assessing the structural and non-structural vulnerabilities in the existing building stock, with specific attention to specific vulnerabilities identified after the
2016 Kaikoura Earthquake, and modeling the behavior of these buildings in a new event.

(2) Identifying, under current conditions, the need for a cordon in the event of a significant earthquake, and describing its likely spatial and temporal extent.

(3) Assessing the likely need to retrofit buildings, and developing an algorithm for prioritizing these retrofits, based on the findings in (1) and (2). 
(4) Developing the regulatory tools and processes that will enable the retrofitting schedule developed in (3).

In a companion paper (Puranam et al. 2019), we describe in detail the history of building construction technology in New Zealand. Based on this analysis and the information collected in the database thus far, we describe the structural vulnerabilities of the existing building stock in the city; and thus provide some answers to question 1 . In what follows, we describe the ways in which the data collected in the database can help us answer questions 2-4.

\subsection{Cordons}

The answer to question 1 depends exclusively on the structural and non-structural engineering information that is contained in the database we developed and on seismic modeling and testing. Question 2, however, already requires the cross-disciplinary assessment and synthesis of disciplinary models, as any decision to cordon is not only dependent on the structural and non-structural integrity of the built environment, but also, for example, on the uses of buildings.

This was most recently observed in Wellington with the City Council's sudden decision in March 2019 to close the Central Library building indefinitely because of newly assessed seismic risk, even though there was no legal obligation to do so. In this case, it is the use of the building by the public and specifically its heavy use by children, that played a decisive role in that decision. "The Wellington Central Library is no ordinary CBD building. It is one of the city's busiest buildings with 3000 visitors a day, including 500 children. The safety of our residents is paramount" (WCC 2019). From a cordoning perspective, this decision is meaningful as the Central Library is located in a major choke-point that connects the two main commercial areas of the city (the Featherston-Lambton Quay and Manners-Cuba-Courtney-Place precincts).

In the City of Christchurch, after its own destructive earthquake in 2011, the government cordoned off the entire center of the city, and did not allow any authorized access for an extended period of time. The cordon was removed only gradually as more buildings were demolished, and it was finally completely removed only in mid 2013, about two and a half years after the earthquake. This emerged as one of the more important policy decisions taken in the aftermath of the earthquake (Chang et al. 2014). The other two decisions singled out in Chang et al. (2014) were the formation of a ministerial-level authority to manage the recovery, and the decision to red-zone large residential areas containing about 8000 houses (Nguyen 2020).

In the long term, it may turn out to be that the CBD cordon decision was the most consequential, as the previously cordoned CBD is the only area in Christchurch that is still visibly far from a full recovery, more than 8 years after the earthquake (Nguyen and Noy 2018).

The decision to cordon in Christchurch, and its extent, were made ad hoc, with little previous consideration of the implication of its extent and its duration. The cordoning disrupted the employment of 50,000 people (Chang et al. 2014) and likely led to substantial spatial re-arrangement of economic activity across the city. This re-arrangement may prove to be permanent, and may hinder future development of the city center. As such, the Wellington City Council has recognized it as a potential risk, and will most likely make every effort to minimize the extent of cordoning in a Wellington event. Planning for such cordoning, through a spatial understanding of the role of each building in the city's transportation network, its economy, and its geography, is necessary for future optimal decision whether to cordon, how much to cordon, and for how long.

While it is difficult to see on-the-record statement on this issue, it is also likely that any cordoning decision will not only be dependent on perceived risk to life (the cost of deciding not to restrict access), but also in the economic, cultural, and social role of the building (the cost of restricting access), and the role of that building within the precinct and within the part of the city in which it is located (for example, in providing services to residents and employees located in other nearby buildings). All of these should be factored in through the assessment of the georeferenced database discussed here.

\subsection{Prioritization of Seismic Retrofits}

For the prioritization part of this project, question 3, we have identified three sets of criteria that will structure the algorithm for prioritization. The mandated legal standard of life safety, of course, is of primal importance. The question we pose here is how to identify and weight the other criteria after life safety considerations have already been incorporated and were found to be insufficient to order an immediate closure of the building (as was done in the case of the Central Library mentioned earlier). Thus, these three sets of criteria will only follow a full consideration of life-safety risk assessment (including identifying buildings that are especially important in this context-for example, because of the high exposure of children).

The three sets of criteria for prioritizing retrofits are: (1) the economic role of the building; (2) the cultural/social role of the building; and (3) its functioning within the transportation network, including its potential impact on the spatial and temporal extent of any cordoning decision in the event of an earthquake.

It is these three criteria, and their measurement in the data included in the database, that will form the backbone 
of the analysis we do in this prioritization companion project. The data included in the database allow users to provide quantifiable measures of these three sets of criteria. One can also potentially standardize them so that they are comparable. The bigger challenge is to identify relative importance attached to each one of these three groups of component measures.

For this last stage, we aim to rely on consultations with experts and stakeholders, using a multi-criteria decision tool, as is done, for example, in Phillips and Bana e Costa (2007). Huang et al. (2011) provide several other examples of applications of multi-criteria decision analysis tools in a spatial-environmental context such as the one under consideration here. One can also imagine different weighting schemes that are used in different applications and for different purposes, so that the robustness of any prioritization needs to be examined relative to the robustness of any weighting scheme used to derive it.

\subsection{Laws and Regulations}

Finally, this prioritization procedure also aims to inform the design of regulatory frameworks whose goal will be to find ways to achieve an outcome that is as close as possible to the retrofitting prioritizations that we identify. For example, in Wellington, renters of office space (private firms, government and other public and non-profit entities) have already responded to the 2011 Christchurch Earthquake by demanding spaces that are well above the $34 \%$ National Building Standards (NBS) threshold that is the legal threshold for "earthquake-prone" buildings. This threshold implies a requirement to retrofit, but after 2011, the market signaled a general consensus that only $67 \%$ of NBS was an acceptable threshold and not the lower $34 \%$ threshold as set by law. Many renters, including central government ministries, started inserting clauses in rental contracts demanding the premises always be above $67 \%$ of NBS (Filippova and Noy 2020).

As such, any regulatory analysis of possible outcomes from any mandatory requirements also needs to assess the ways markets will react to any regulatory change. For example, densification of the Wellington CBD, which is expected to nearly double in population in the next 25-30 years with over 15,000 new residents, will prompt conversion of many lower quality buildings and ageing commercial buildings to apartments, and is likely to change the risk profile of the city (WCC 2015). How that is done, taking into account both legal constraints and market forces, needs to be assessed.

The prioritizations implied by the multi-criteria analysis suggested above will also require legal tools to manage. As such, legal analysis of the viability of current tools, and of the feasibility of designing ones that are fit for this purpose, is also part of the required research.

\section{Conclusion}

Ultimately, this multi-disciplinary database aims to provide a vehicle for the generation and use of the best scientific knowledge about the expected seismic performance of buildings, the economic and social impact of building failures including the downstream consequences associated with their failure, and introduce new ideas regarding the prioritization of retrofits and the optimized regulatory structure to address this risk.

Finally, we envision this as a first step in the ultimate creation of a building inventory database for the whole of New Zealand, one that will enable the pursuit of much better-informed public policy, not only within the context of seismic risk management (an important goal in its own right in an earthquake-prone country), but also for other purposes. For example, risks associated with climatic change (for instance, sea level rise) could also be better managed if a building inventory database such as the one described here was available for all coastal, pluvial, and fluvial zones. Beyond the management of other disaster risks, however, such a building inventory database can enable local and central governments to improve planning for many other purposes, even for such inevitable changes as population aging.

Acknowledgements This project was (partially) supported by QuakeCoRE, a New Zealand Tertiary Education Commission funded center. This is QuakeCoRE Publication Number 0440.

Open Access This article is licensed under a Creative Commons Attribution 4.0 International License, which permits use, sharing, adaptation, distribution and reproduction in any medium or format, as long as you give appropriate credit to the original author(s) and the source, provide a link to the Creative Commons licence, and indicate if changes were made. The images or other third party material in this article are included in the article's Creative Commons licence, unless indicated otherwise in a credit line to the material. If material is not included in the article's Creative Commons licence and your intended use is not permitted by statutory regulation or exceeds the permitted use, you will need to obtain permission directly from the copyright holder. To view a copy of this licence, visit http://creativecommons. org/licenses/by/4.0/.

\section{References}

Anagnos, T., M.C. Comerio, C. Goulet, and P.J. May. 2012. Developing regional building inventories: Lessons from the field. Earthquake Spectra 28(4): 1305-1329.

Anagnos, T., M.C. Comerio, and J.P. Stewart. 2016. Earthquake loss estimates and policy implications for nonductile concrete buildings in Los Angeles. Earthquake Spectra 32(4): 1951-1973. 
Brundson, D., K. Elwood, and R. Henry. 2017. Wellington City Council Targeted Assessment Programme. Kestrel Group and QuakeCoRE report. https://wellington.govt.nz/ /media/aboutwellington/emergency-management/files/targeted-assessmentprogramme-summary.pdf. Accessed 10 Oct 2020.

Chang, S., J.E. Taylor, K.J. Elwood, E. Seville, D. Brunsdon, and M. Gartner. 2014. Urban disaster recovery in Christchurch: The central business district cordon and other critical decisions. Earthquake Spectra 30(1): 513-532.

Comerio, M. 2000. The economic benefits of a disaster resistant university: Earthquake loss estimation for UC Berkeley. Working paper 2000-02. Institute of Urban and Regional Development, University of California, Berkeley, USA. https:// escholarship.org/uc/item/78g7j8jq. Accessed 10 Oct 2020.

Comerio, M.C., and T. Anagnos. 2012. Los Angeles inventory: Implications for retrofit policies for nonductile concrete buildings. 15th World Conference on Earthquake Engineering, 24-28 September 2012.

Falcon Consulting. 2019. Unreinforced masonry buildings programme debrief report to Wellington City Council. https:// wellington.govt.nz/ /media/services/rates-and-property/earth quake-prone-buildings/files/urm/umr-debrief-final-report. pdf?la=en. Accessed 10 Oct 2020.

Filippova, O., and I. Noy. 2020. Preventing buildings from falling down: Challenges for earthquake-strengthening policy in smalltown New Zealand. Disasters 44(1): 179-204.

Grant, D., J. Bommer, R. Pinho, G. Calvi, A. Goretti, and F. Meroni. 2007. A prioritization scheme for seismic intervention in school buildings in Italy. Earthquake Spectra 23(2): 291-314.

Hancilar, U., I. El-Hussain, K. Sesetyan, A. Deif, E. Cakti, G. AlRawas, E. Safak, and K. Al-Jabri. 2018. Earthquake risk assessment for the building inventory of Muscat, Sultanate of Oman. Natural Hazards 93(3): 1419-1434.

Harris, C. 2016. "Musical chairs" as quake closes 11 per cent of Wellington CBD space. https://www.stuff.co.nz/business/prop erty/87287789/musical-chairs-as-quake-closes-11-per-cent-ofwellington-cbd-space. Accessed 10 Oct 2020.

Huang, I.B., J. Keisler, and I. Linkov. 2011. Multi-criteria decision analysis in environmental sciences: Ten years of applications and trends. Science of The Total Environment 409(19): $3578-3594$.

Jaiswal, K.S., and D.J. Wald. 2008. Creating a global building inventory for earthquake loss assessment and risk management. U.S. Geological Survey open-file report 2008-1160. Reston, VA: U.S. Geological Survey.

Kircher, C.A., R.V. Whitman, and W.T. Holmes. 2006, HAZUS earthquake loss estimation methods. Natural Hazards Review 7(2): 45-59.

Langridge, R.M., W.F. Ries, N.J. Litchfield, P. Villamor, R.J. Van Dissen, D.J.A. Barrell, M.S. Rattenbury, D.W. Heron, et al. 2016. The New Zealand active faults database. New Zealand Journal of Geology and Geophysics 59(1): 86-96.

Nguyen, C. 2020. Homeowners' choice when the government proposes a managed retreat. International Journal of Disaster Risk Reduction 47: Article 101543.
Nguyen, C., and I. Noy. 2018. Measuring the impact of insurance on urban recovery with light: The 2010-2011 New Zealand earthquake. CESifo working paper. Munich: CESifo $\mathrm{GmbH}$.

Palermo, V., G. Tsionis, and M.L. Sousa. 2018. Building stock inventory to assess seismic vulnerability across Europe. Luxembourg: Publications Office of the European Union.

Phillips, L.D., and C.A. Bana e Costa. 2007. Transparent prioritization, budgeting and resource allocation with multi-criteria decision analysis and decision conferencing. Annals of Operations Research 154(1): 51-68.

Puranam, A., O. Filippova, J. Pastor-Paz, M. Stephens, K.J. Elwood, N. Ismail, I. Noy, and E. Opabula. 2019. A detailed inventory of medium- to high-rise buildings in Wellington's central business district. Bulletin of the New Zealand Society for Earthquake Engineering 52(4): 172-192.

Russell, A.P., and J.M. Ingham. 2010. Prevalence of New Zealand's unreinforced masonry buildings. Bulletin of the New Zealand Society for Earthquake Engineering 43(3): 182-201.

Sucuoğlu, H., A. Yakut, A. Özmen, and J. Kubin. 2015. Seismic risk prioritization and retrofit cost evaluation of code-deficient RC public buildings in Turkey. Earthquake Spectra 31(1): 601-614.

Theilen-Willige, B., P. Savvaidis, I.N. Tziavos, and I. Papadopoulou. 2012. Remote sensing and Geographic Information Systems (GIS) contribution to the inventory of infrastructure susceptible to earthquake and flooding hazards in north-eastern Greece. Geosciences 2(4): 203-220.

USGS (U.S. Geological Survey). 2014. Where do earthquakes occur? https://www.usgs.gov/faqs/where-do-earthquakes-occur?qtnews_science_products $=0 \# q$ t-news_science_products. Accessed 10 Oct 2020.

Walsh, K.Q., R. Jafarzadeh, N.M. Short, and J.M. Ingham. 2016. Seismic risk management of a large public facilities portfolio: A New Zealand case study. Facilities 34(13/14): 809-827.

Walsh, K.Q., P.A. Cummuskey, R. Jafarzadeh, and J.M. Ingham. 2017. Rapid identification and taxonomical classification of structural seismic attributes in a regionwide commercial building stock. Journal of Performance of Constructed Facilities 31(1): Article 04016067.

WCC (Wellington City Council). 2015. Central city population growth. https://wellington.govt.nz/your-council/plans-policiesand-bylaws/urban-development/managing-growth/central-citypopulation-growth. Accessed 10 Oct 2020.

WCC (Wellington City Council). 2019. Council chief executive makes necessary decision to close central library: "Safety is our number one priority". Press release, 19 March 2019. Wellington, New Zealand: WCC.

Yathon, J., P. Adebar, and K.J. Elwood. 2017. A detailed inventory of non-ductile concrete shear wall buildings. Earthquake Spectra 33(2): 605-622.

Yepes-Estrada, C., V. Silva, J. Valcárcel, A.B. Acevedo, N. Tarque, M.A. Hube, G. Coronel, and H.S. María. 2017. Modeling the residential building inventory in South America for seismic risk assessment. Earthquake Spectra 33(1): 299-322. 